\title{
EL PENSAMIENTO SOCIAL DE LAS MUJERES NEGRAS A TRAVÉS DE LA REVISTA ADELANTE (1935-1939)
}

\author{
Black women's social thought through the journal Adelante (1935-1939)
}

\author{
Valentina Salinas Carvacho*
}

\begin{abstract}
RESUMEN
El artículo analiza el pensamiento social de las mujeres afrocubanas tal como se articula en la revista Adelante (1935-1939), teniendo como eje de análisis su posición ante los problemas de "género" y de "raza". Sus escritos buscan poner en tensión la condición social de la mujer en Cuba, haciendo hincapié en las dificultades particulares que vive la mujer negra, producto de las subalternizaciones por "género" y por "raza" a las que se ve expuesta, pero al mismo tiempo reproducen ciertos estereotipos de la época, fijando la identidad de la mujer como madre y asumiendo un proyecto de ilustración acorde con dicha identificación.
\end{abstract}

Palabras clave: mujeres afrocubanas, revista Adelante, género, raza, pensamiento feminista negro.

* Estudiante del Programa de Magíster en Estudios Latinoamericanos, Universidad de Chile. Santiago, Chile. Correo electrónico: eu.valesalinas@gmail.com

Artículo recibido el 31 de agosto de 2017. Aceptado el 6 de marzo de 2018. 


\begin{abstract}
The article analyzes the social thinking of Afro-Cuban women as articulated in the magazine Adelante (1935-1939), having as its axis of analysis their position on the problems of "gender" and "race". The writings stress the social status of women in Cuba, emphasizing the particular difficulties experienced by black women, as a result of their subalternization by "gender" and "race". At the same time, these writings reproduce certain prevailing stereotypes during the time period by reinforcing the identity of woman as that of mother.
\end{abstract}

Keywords: Afrocuban women, journal Adelante, gender, race, black feminist thought.

\title{
1. Introducción
}

Durante las primeras décadas del siglo XX diversos actores políticos y sociales se organizaron para hacer frente a los conflictos que vivía la Cuba republicana. Tanto la política imperialista norteamericana, como las discriminaciones mantenidas por la elite a los grupos históricamente subordinados, llevaron a los intelectuales a desarrollar un discurso nacionalista antiimperialista de matriz martiana, y una lucha política en contra de la exclusión de dichos grupos. Así, negros y mujeres enarbolaron sus propias banderas de lucha afiliándose a partidos y agrupaciones de diversas orientaciones. A pesar de la incorporación masiva de estos actores al espacio público, la mayor parte de los activistas e intelectuales negros eran hombres y, por su parte, las mujeres que encabezaron el movimiento feminista eran blancas, lo cual nos revela que los mismos individuos que pretendían acabar con dichas exclusiones reproducían los mecanismos clásicos de discriminación ${ }^{1}$. Pero será la revolución de 1933, momento de ebullición de la movilización política que existía en el país, aquella que dará impulso a que los distintos actores funden nuevas organizaciones y proyectos editoriales a partir de alianzas e integraciones. Así nacerá la asociación Adelante en 1933, sociedad de jóvenes

\footnotetext{
1 La presencia de las mujeres negras en las agrupaciones vigentes fue escasa, aunque no inexistente. En ciertas circunstancias, el movimiento feminista buscó integrar a las afrocubanas en sus filas, y por su parte, los hombres negros se refirieron a los problemas de género e instaron a las mujeres a participar en sus periódicos y asociaciones. Por ejemplo, Francisca Arce de D'ou, esposa de Lino D'ou, participó durante un periodo en Lyceum de la Habana, institución cultural femenina compuesta por mujeres blancas (Urrutia, 1933, p. 14). Asimismo, algunas afrocubanas interesadas en la obtención del sufragio se afiliaron entre 1914 y 1917 al Partido Nacional Sufragista (Rubiera, 2011, p. 180).
} 
afrocubanos de clase media que se propuso denunciar la discriminación racial que sufrían los negros en Cuba, así como velar por su mejoramiento cultural, económico y político, para lo cual crearon la revista Adelante (19351939), medio de difusión de sus actividades y espacio de debate intelectual y político. Adelante fue una publicación mensual de divulgación popular que, con un total de 45 números, entregó al público lector artículos breves sobre problemas de contingencia nacional que afectaban a los afrocubanos, y en menor medida, poemas y cuentos que abordaran dichos problemas. En tanto se declaró heredera de los postulados martianos sobre la confraternidad cubana y la unidad en la lucha, formó parte de los pocos periódicos afrocubanos que incorporó la temática sobre la condición de la mujer en la nación, siendo de gran relevancia por presentar artículos feministas escritos por mujeres negras. Entre sus integrantes encontramos a Cloris Tejo, Jorge Santana Fernández, Tomás Acuña Lazcano, Gustavo Urrutia, Tomás Savignon, Consuelo Serra, Ángel Pinto y Alberto Arredondo, por mencionar a algunos. A pesar de la inexistencia de fuentes tanto respecto a su tiraje, como a la cantidad de suscriptores que logró captar, sabemos que la revista tuvo gran impacto en la opinión pública, lo cual puede extraerse de los balances que los mismos colaboradores hicieron. A partir de mayo de 1937 anunciaron su cambio de sede producto de la gran cantidad de personas que visitaban el local para intercambiar opiniones y del "progresivo aumento de la circulación" (Editores, 1937 xxiv, p. 4)². Este trabajo se propone analizar cómo se posicionaron las intelectuales afrocubanas de Adelante ante los problemas sociales que aquejaban a las mujeres en general, y a las mujeres y hombres negros en particular. Se postula que su pensamiento estuvo imbuido, desde el punto de vista de "género", por una identidad femenina basada en la maternidad, y desde el punto de vista de "raza", por una ideología articulada en torno a la promesa de la unidad racial y a la superación cultural y social de los negros. Ambas categorías, "raza" y "género" se transformaron en interpelaciones identitarias que llevaron a las afrocubanas a resolver a

\footnotetext{
2 Sin embargo, desde el tercer aniversario las dificultades de mantener la publicación a nivel nacional, se dejaron ver en la declarada ausencia de capital económico y en la falta de "arraigo en la opinión pública del país" (Editores, 1938 xxxvi, p. 3). Es difícil esgrimir hipótesis que puedan explicar el desinterés del público lector debido a la inexistencia de fuentes al respecto. Es de esperarse que las alianzas de los grupos de izquierda durante este mismo año -en específico del PCC con el estado-, los planes sociales y económicos implementados por Gerardo Machado, así como la esperanza de la ciudadanía de mejorar la situación del país con la asamblea constituyente que estaba próxima a venir, expliquen en alguna medida el descenso de suscriptores y la desilusión de los adelantistas. A pesar de este hostil escenario, la publicación logró sobrevivir nueve meses más, no llegando a alcanzar el cuarto aniversario, y sin anunciarse su cierre.
} 
partir de estas inscripciones los conflictos que las aquejaban producto de las desigualdades que seguían sosteniéndose en la Cuba republicana.

\section{Las organizaciones feministas durante el periodo republicano}

La conformación de asociaciones feministas comienza a desarrollarse en la década de 1910. Así, en 1913 se funda el Partido Nacional Sufragista, en 1918 el Club Femenino y en 1921 la Federación Nacional de Asociaciones Femeninas, la cual permitió la organización de los dos primeros congresos nacionales de mujeres (Ramírez, 2014, p. 788). Las distintas agrupaciones nacieron al calor de las discusiones en torno al sufragio, a los derechos laborales, a la necesidad de una mayor protección social y una ley de divorcio, por mencionar algunos de los temas más importantes que abordaron ${ }^{3}$. Muchas de las demandas por mayores derechos fueron aprobadas antes de 1918 sin una fuerte insistencia por parte del movimiento feminista, en tanto los políticos cubanos requerían modernizar la nación, siendo la educación gratuita, los derechos de propiedad o la legislación laboral elementos fundamentales para lograrlo (Stoner, 1992, p. 57). Fue el clima de politización que se desarrollará entre 1925 y 1940 el que fortalecerá a las distintas agrupaciones de mujeres, enriqueciendo los debates y aumentando el número de afiliadas. La presión que su capacidad de trabajo y movilización generará verá sus frutos en la aprobación del sufragio en 1934, tras arduas luchas contra la dictadura de Machado.

Como señala K. Lynn Stoner (1992), el movimiento feminista estuvo lejos de ser homogéneo en sus perspectivas ideológicas, así como en las soluciones propuestas para enfrentar los problemas de género. Sin embargo, hubo un punto de consenso que sirvió de horizonte identitario: el enaltecimiento de la maternidad "y el deseo de ser un complemento para los varones" (p. 20). En efecto, en la mayor parte de los debates, ya sean de naturaleza política, cultural o social, la importancia de la mujer como madre de los hijos, de la patria o de la humanidad se encuentra presente. Tanto las feministas conservadoras como las radicales, ensalzaron a la mujer como portadora de una moral superior a la masculina, dotada de una comprensión basada en el amor maternal ${ }^{4}$. Estas ideas tenían como pilar de base un argumento esencialista, asumiendo que existía una naturaleza femenina dada por su "sexo", la cual, lejos de conflictuar

\footnotetext{
${ }^{3}$ El Club Femenino también se preocupó del problema de la prostitución, el alcoholismo, el trabajo infantil o la pena de muerte (Ramírez, 2014, p. 788).

${ }^{4}$ Por ejemplo, Sabas Alomá (2003), feminista radical afirmó que "cada mujer es una hembra en esencia y una madre en potencia" (p. 60).
} 
a las dirigentes, se transformó en uno de los símbolos más importantes de sus discursos. Esta cualidad del feminismo cubano fue tan importante que en los congresos de mujeres de 1923, 1925 y 1939 "las participantes delinearon una ideología feminista que hacía de la maternidad la piedra angular de la revolución de la mujer" (1992, p. 265). Como veremos, las mujeres afrocubanas de Adelante no estuvieron alejadas de este discurso. Antes bien, en sus escritos su identificación con la maternidad es explicita. En ese sentido no se diferenciaron del resto de las mujeres, reproduciendo los tradicionales roles de género. El mérito de las feministas en general no se basó en cuestionar los principios patriarcales del poder, sino en movilizar el rol materno del espacio privado al público, prolongando el rol de madre hacia la nación y la humanidad. Ese rol implicó moralizar instituciones como la escuela, las fábricas o el estado, redefiniendo la importancia de la mujer en dichos espacios.

Las mujeres blancas se preocuparon muy poco del problema racial, de modo que si las afrocubanas entraron en su campo de visión fue en condición de obreras. Las feministas radicales criticaron las malas condiciones en que las mujeres debían trabajar al interior de las fábricas e insistieron en que se promulgaran leyes laborales para ellas (Stoner, 1992, p. 233). Durante el Segundo Congreso de Mujeres Ofelia Domínguez Navarro y Pilar Jorge de Tella pusieron de relieve la necesidad de aliarse con las mujeres trabajadoras que "sufrían la mayor injusticia social" (1992, p. 235). Esto demuestra que la "raza" no era una categoría de análisis utilizada en sus discursos, lo que contrasta con las reflexiones de algunos intelectuales del periodo, que sí se refirieron a la situación de las afrocubanas al ser racializadas como mujeres negras ${ }^{5}$, y por tanto subalternizadas no solo desde el punto de vista de "género", sino también a partir de su color de piel. Hubo que esperar a la década de 1930 para que los conflictos de las llamadas mujeres de color calaran con más profundidad en las luchas feministas. Así, en el Tercer Congreso Nacional de Mujeres de 1939 la situación había cambiado, en tanto no solo acudieron afrocubanas ${ }^{6}$, sino que se

\footnotetext{
5 Por ejemplo, en la sección “Armonías” del Diario La Marina, Gustavo Urrutia se refirió a la condición de las mujeres negras: "La negra. Como mujer y como negra: Beato el que sufre. No tiene conflictos por sufrirlos todos... y todo contribuye a que sea mantenedora inconcusa de los principios de igualdad proclamados por su sexo y por su raza" (Urrutia, 1928, p. vi). Por su parte, Agustín Alarcón aludió directamente a la triple subordinación que sufría: "Las masas negras, como las masas de mujeres pobres, sufren en dicho régimen una doble opresión: la general, de clase y la específica, de raza o sexo. (La mujer negra obrera sufre tres: la de clase, la de raza y la de sexo). A la general la distinguimos por explotación, a la específica, por discriminación" (Alarcón, 1937 xxvii, p. 12).

${ }^{6}$ John A. Gronbeck-Tedesco (2015) registra que el 30\% de las mujeres que acudieron a este Congreso eran negras (p. 255).
} 
hicieron cargo de parte de la organización del congreso ${ }^{7}$, presentaron ponencias y se agregó a la agenda de discusión el problema de la mujer negra ${ }^{8}$. Esta apertura ha sido leída como parte de una maduración del movimiento, puesto que logró abordar la subordinación de la mujer en relación con otras formas de opresión (Stoner, 1992, p. 221).

\section{La caída del machadiato y la radicalización de los movimientos sociales}

Entre 1925 y 1933 el país se encontró sumido en una dictadura al mando de Gerardo Machado. La sociedad civil no respondió pasivamente ante un clima político dominado por el caudillismo, la represión y la tutela permanente de Norteamérica, antes bien, su capacidad de movilización y presión inédita culminó en la revolución social de 1933 y el establecimiento del Gobierno Revolucionario Provisional de Ramón Grau San Martín. Una de las cuestiones más significativas de este proceso fue el paso de un gobierno oligárquico hacia un estado moderno y un aprendizaje político por parte de los movimientos sociales que radicalizaron los discursos y las prácticas en aras de consolidar una verdadera revolución (Whitney, 2001). En este breve mandato reformas muy significativas se produjeron: se derogó la Enmienda Platt, se otorgó la autonomía universitaria exigida por los estudiantes, las mujeres obtuvieron el derecho a voto y se estableció la jornada laboral de ocho horas, entre varias otras medidas9. La obtención del derecho a sufragio llevó a la mayoría de las

\footnotetext{
${ }^{7}$ Consuelo Silveira, afrocubana y líder del movimiento obrero afrocubano de La Habana, sirvió como viceministro de finanzas del comité. Ana Etchegoyen de Cañizares, profesora afrocubana de la Universidad de La Habana y escritora de la revista Adelante, fue seleccionada como secretaria de correspondencia. El comité ejecutivo también incluyó a varias mujeres negras como vocales (miembros votantes del comité): Teresa García del Sindicato de Trabajadores del Tabaco de La Habana, Angelina Edreira, educadora e historiadora, Elvira Rodíguez, líder la feminista y abogada Catalina Pozo Gato, la farmacéutica Esperanza Sánchez Mastrapa y la educadora y escritora María Dámasa Jova de Santa Clara (Brunson, 2011, p. 236). ${ }^{8}$ Los temas de discusión de este congreso fueron: "La mujer y los códigos", "La mujer y el niño", "La mujer y las leyes sociales", "La mujer joven y sus problemas específicos", "La mujer y la asistencia social", "La mujer y la cultura", "La mujer y los prejuicios raciales", "La mujer y la política", "La mujer y la paz". Dentro del ítem "La mujer y los prejuicios raciales", los puntos a tratar eran: 1 . Situación de la mujer negra en Cuba. Su problema social, cultural y económico. 2. El prejuicio racial y el niño. Igualdad del niño negro y el niño blanco. 3. Igualdad legal y real de las mujeres negras y blancas en la vida cubana. 4. Los prejuicios raciales y sus manifestaciones en el mundo: lucha contra ellos. 5. Participación de la raza negra en la formación de nuestra nacionalidad (Yañez, 2003, p. 95).

${ }^{9}$ A pesar de que no se decretaron leyes vinculadas a la igualdad racial, este tema adquirió una centralidad mayor, y se transformó en una responsabilidad de estado. Al respecto, los afrocubanos denunciaron que a pesar de que en la Constitución de 1901 existía un principio de igualdad legal, en la práctica la discriminación seguía operando (De la Fuente, 2000, p. 295).
} 
mujeres activistas a focalizarse más en los problemas sociales, dando "muestras de una nueva identidad política" (Stoner, 1992, p. 177). Así, entre 1934 y 1940 las feministas influyeron para que los principios sociales por los que habían abogado durante los años veinte desde la perspectiva de la beneficencia fueran ahora cubiertos por el Estado, como "financiar la educación de la mujer, proporcionar servicios de bienestar social y maternidad, y a suprimir los horrores en las cárceles de mujeres" (1992, p. 179).

¿Cómo analizar el proyecto de Adelante en este contexto y el lugar que ocupaba el discurso de género en su interior? En primer lugar es necesario señalar que el horizonte principal de la revista, y acorde con los de la misma asociación, fue denunciar y terminar con la discriminación racial en todos los ámbitos, así como apoyar "el mejoramiento de las clases populares del país injustamente preteridas e inferiorizadas" (Editores, 1936 xii, p. 5). Para lograrlo divulgaron a través de sus páginas artículos sobre la discriminación racial y de "clase", reflexiones críticas sobre el concepto de "raza", ensayos de denuncia al imperialismo, así como información sobre las academias, clases de preparatoria "para ingresar a los institutos y escuelas normales, instrucción primaria, corte y costura, inglés, etc." (Editores, 1937 xxvii, p. 4), y "ciclos de Conferencias... y otros actos de divulgación cultural" que la asociación organizó (Editores, 1938 xxxvi, p. 14) ${ }^{10}$.

Como ya mencionamos, Adelante no se enfocó solo en el problema racial, sino que solidarizó con otros grupos oprimidos con el fin de "obtener las reivindicaciones inmediatas a que tiene derecho la parte de esa sociedad que hoy no la disfruta" (Editores, 1938 xxxvi, p. 13). En efecto, los columnistas advirtieron que las formas de subalternización por "sexo" y "raza" tenían varios puntos en común, resaltando que ambas habían sufrido "de la antigua condición vegetativa y esclavizada" (Editores, 1937 xxi, p. 3). Gustavo Urrutia reconoció que "la Historia ha venido acumulando iniquidades a través de los siglos sobre la mujer, el campesino, el obrero y las diversas razas de color", reflexión que le llevará a considerar que la revolución "sólo se logrará por una noble aligación de los diversos intereses, o sea incorporando sus reivindicaciones particulares de sexo, de raza y de clase al programa general de la Revolución" (Urrutia,

\footnotetext{
$10 \mathrm{Su}$ proyecto se sostuvo, en términos económicos, a partir tanto del esfuerzo de intelectuales y profesionales de clase media - a través de sus aportes individuales y de la realización de eventos (colectas, festivales) - de las ventas y cuotas que los suscriptores debían pagar por asociarse a ella, y de los anuncios que publicitaron, lo cual le dio una clara autonomía ideológica con respecto al estado. Así, crearon un Fondo Pro-imprenta, recaudando capital económico de entidades como el Club Atenas, la Sociedad Club Oriente de Santa Lucía, la Sociedad Cosmopolita "Juguaní Club", la Federación Provincial de Sociedades Cubanas de Orientes y de miembros y simpatizantes de Adelante.
} 
1935 ii, p. 6). Dicha idea explica la importancia que dieron a los debates sobre "género" y a la contribución activa de las mujeres en la asociación. Esto es aún más relevante si consideramos que tradicionalmente las sociedades afrocubanas habían dado un rol muy pasivo a las mujeres, apartadas en comités de damas (De la Fuente, 2000, p. 282), o reproduciendo discursos que fomentaba que se mantuvieran como "ángeles del hogar"11. En cambio, las mujeres de Adelante escribieron activamente en la revista y ocuparon cargos en la secretaría de cultura y tesorería, los cuales si bien eran de carácter ejecutivo, representan un avance en términos de participación femenina al interior de las sociedades negras ${ }^{12}$. Además, para promover la ilustración cívica y cultural de las mujeres de color formaron en 1935 la Asociación Cultural Femenina, "la principal asociación afrocubana de mujeres de este periodo"13 (Guridy, 2010, p. 183), en la cual la mayor fuerza fue Ana Echegoyen. Así, intentaron educar a las analfabetas celebrando festivales pro-aulas, entre varias otras actividades (Acuña, 1938 xxxvii, p. 18).

¿Quiénes fueron las escritoras de Adelante? Cuatro mujeres afrocubanas destacan por ser las que más colaboraron con artículos en la revista: Consuelo Serra, Ana Etchegoyen, Calixta Hernández y Cloris Tejo Hernández. Además de ellas se publicó un texto de: Arabella Oña, Rosa Hilda Zell, Elia Aguilera Martínez, María Luisa Sánchez y algunos de María Villar Buceta. Finalmente existen dos publicaciones de mujeres afroamericanas, una de Anna Graves y otra de Cecilia Eggleston. Lamentablemente no hay referencias respecto a Oña, Zell, Sánchez ni Martínez, pero sí de las colaboradoras más activas. Todas ellas eran miembros de la intelligentsia afrocubana. Consuelo Serra no solo fue hija del destacado patriota y líder de la independencia Rafael Serra,

\footnotetext{
${ }^{11}$ Por ejemplo, una de las agrupaciones negras más importantes de la Isla, el Club Atenas, tenía como requisito para obtener la membresía plena el ser hombre. Además sus integrantes presionaron a las mujeres para que fueran capaces de constituir familias estables (De la Fuente, 2000, p. 241).

${ }^{12}$ En ese sentido considero errada la lectura que realiza Ramírez Chicharro (2016) en relación a la postura de la Asociación Adelante sobre el rol de la mujer. El autor indica que Adelante, al igual que Club Atenas y otras sociedades negras defendieron que "las mujeres deben ser dueñas de su hogar, dedicarse a su cometido biológico de la reproducción, cuidar a sus hijos y recluirse en el espacio privado por su presunta incapacidad para enfrentarse con asuntos públicos" (p. 149). Sin embargo, los mismos editores de Adelante en su número XXI afirman: "Impedir o refrenar a la mujer el desarrollo de estas facultades y derechos innegables, queriendo reducir su actuación total a tareas domésticas y funciones decorativas en los tradicionales 'comités de damas', es más que una simple equivocación... Por eso mantenemos que es preciso dar a la mujer negra, participación directa y ejecutiva en nuestros destinos sociales, con igualdad absoluta de derechos y deberes. Que pueda ser en cada entidad un miembro más, sin la menor diferencia restrictiva" (Editores, 1937 xxi, p. 3).

13 "The leading afro-cuban women's association of this period"
} 
sino que además obtuvo títulos universitarios en filosofía y pedagogía (De la Fuente, 2000, p. 217), fue profesora de inglés en la Escuela Normal de Maestros de La Habana y fundadora de la Escuela Hogar Consuelo Serra. Por su parte, Ana Echegoyen fue la primera mujer afrocubana que ocupó una cátedra en la Universidad de La Habana (Hernández, 1938 xxxiii, p. 13). Calixta Hernández fue profesora de instrucción pública, y Cloris Tejo, abogada y secretaria de cultura de Adelante $^{14}$. El hecho de que la mayoría de las mujeres se dedicara al ejercicio docente nos permite comprender su cercanía con los temas relacionados a la educación, ligados ellos a su vez con la maternidad, como analizaremos en el siguiente apartado.

\section{En búsqueda del progreso espiritual: Educación, maternidad y problema racial}

Uno de los problemas que más preocupaba a la Asociación Adelante era el de cómo educar a los individuos de color para la "superación" cultural y social de su "raza". Por ende, dentro de los fines últimos de sus integrantes se encontraba el de instruir a los negros para que se integraran a la civilización, dejando el retraso en que se encontraban producto de la esclavitud. Dicha necesidad de instrucción se reflejaba en artículos donde se reconocía a destacados intelectuales y patriotas afrocubanos con el fin de enaltecer la capacidad de los negros, otros dedicados a condenar ciertas prácticas de la clase baja de color, como la realización de Congas (en tanto se distanciarían de este ideal de ciudadanos letrados y civilizados) y algunos donde se celebraron las nuevas expresiones que los afrocubanos estaban creando a partir del auge del negrismo.

Las mujeres se refirieron a los debates en torno a la educación, cultura y progreso de los negros, pero en estrecho vínculo con el rol de la mujer y de la identidad femenina para el desarrollo espiritual de una nueva "raza cubana" (Serra, 1935 v, p. 10). En términos generales, las adelantistas entendieron que

\footnotetext{
14 Es significativo que nos encontremos ante mujeres profesionales que lograron desempeñarse laboralmente en sus carreras, en tanto uno de los mayores conflictos de la clase media negra residió justamente en su imposibilidad de obtener nichos laborales a pesar de su alta calificación. Este conflicto aparece representado en la revista, por ejemplo en el cuento “¡Nunca!” de Ángel Alonso Scull (1935 iv), el cual narra la tragedia de un joven negro que trabajaba en un ingenio, y que logró estudiar medicina, pero con fatales resultados, en tanto nadie acudía a su consulta: “¿Me pintó que el bufete de un médico era esta cueva fría y desierta?” (p. 20). Alberto Arredondo aseguró que la clase media negra podría “escribir una novela sobre los extraordinarios obstáculos con que tropezó para ascender en el peldaño de la profesionalidad" (Arredondo, 1939, p. 61).
} 
la educación era uno de los grandes pilares que les llevaría a terminar con los infortunios que padecían los grupos subordinados, llegando algunas a afirmar que "el problema negro, el problema cubano, como todos los problemas de naturaleza social, son problemas de educación" (1935 v, p. 10). Aunque esta última apreciación no parece ser compartida por la mayoría de los colaboradores, efectivamente se deja ver en la mayor parte de los escritos de las intelectuales la necesidad de crear más centros de enseñanza para que negros, mujeres y niños reciban una educación. Ahora bien, un punto que define su postura es que la enseñanza de la mujer no versaría sobre los mismos contenidos que la de los hombres. Al igual que las activistas del movimiento feminista, las adelantistas reprodujeron los roles clásicos de "género", basados en asignar una identidad específica a los individuos por su cuerpo sexuado, lo que en la práctica implicó asumir que cada persona, en tanto mujer u hombre, tenía determinadas funciones que cumplir en la sociedad ${ }^{15}$. Así, enfatizaron que una manera de elevar el nivel intelectual de la mujer sería entrenándola "para la vida del hogar de madre futura" (Aguilera, 1937 xxvii, p. 10). El ideal era que aprendiesen de "contabilidad aplicada a la administración doméstica, conocimiento de cocina, costura, higiene doméstica, estética del hogar" (1937 xxvii, p. 10 ${ }^{16}$. Además se les prepararía para que pudieran ser independientes económicamente solo en el caso de que fuera necesario, en tanto su primera responsabilidad estaba al interior del espacio doméstico. Otro de los temas que debían manejar era la instrucción sexual y la eugenesia, puesto que "toda mujer debe conocer suficientemente a fin de hallarse en aptitud de resolver con algunas probabilidades de éxito los problemas del amor y de la maternidad en los cuales se resume el sentido fundamental de su existencia" (1937 xxvii, p. 10).

Por lo general el mensaje de las adelantistas siempre buscó interpelar a las mujeres obreras y/o negras. Así, Calixta Hérnandez (1935 ii) puso de relieve que las ligas de protección social y clubes de damas no llegaban a todas las mujeres, quedando las obreras sin la posibilidad de desarrollarse "en lo

\footnotetext{
${ }^{15}$ La crítica feminista de los años setenta y ochenta se dedicó a desestructurar la asociación entre el cuerpo sexuado y la identidad. Así, y como afirma Marta Lamas (2000) “el género se conceptualizó como el conjunto de ideas, representaciones, prácticas y prescripciones sociales que una cultura desarrolla desde la diferencia anatómica entre mujeres y hombres, para simbolizar y construir socialmente lo que es "propio" de los hombres (lo masculino) y "propio" de las mujeres (lo femenino) (p. 2).

${ }^{16}$ Aunque este pensamiento fue muy extendido en la época por las mismas feministas, algunas combatieron la idea de que la mujer debía mantenerse en el hogar, y de hecho, visualizaron que era justamente en este espacio donde se mantenía a la mujer esclavizada. Ese fue el caso de las anarquistas españolas: "Hemos dicho muchas veces que la independencia de la mujer es inseparable de su independencia económica. Hemos dicho que "el hogar" era, en la mayoría de los casos, un símbolo de esclavitud” (Editorial, 1937, s/p).
} 
físico y lo espiritual" (p. 14). Era menester evitar que cayeran "en las garras de la prostitución" (p. 14.), y que pudieran convertirse en ejemplo de virtud para educar a los hijos y hombres del porvenir. La virtud era uno de los valores asociados a la honorabilidad, y se transformó durante los años treinta en un ideal bien frecuente para la clase media negra. En este periodo "la creencia en que la educación, y la adopción de valores conservadores elitistas, como la de los roles de género, estabilidad familiar, valores morales superiores y decencia"17 (Arnedo-Gómez, 2016, p. 9) eran mecanismos de ascenso social, fue algo que también las y los adelantistas defendieron a través de sus escritos. Para ellos, que habían sido interpelados por los discursos racistas que apelaban a la incapacidad de los negros de tener familias estables, se hacía aún más urgente constituir hogares sólidos para derribar dichos prejuicios.

Si la redefinición del rol de la mujer en la república pasaba por entregar conocimientos sobre educación en el hogar, en el caso del "problema negro", Consuelo Serra propuso reorientar los contenidos de la enseñanza escolar, dando cuenta de los ejemplos de unión racial que habían existido en la historia de Cuba. Así, recordó la relación entre Panchito Gómez Toro y Antonio Maceo en el periodo de la Independencia, como fuente de inspiración para fomentar la unidad entre blancos y negros. Uno de los mayores problemas que Serra detectó fue justamente el desconocimiento que tenían los adolescentes sobre las ilustres figuras que tanto habían elevado "el nivel moral de vida cubana" (Serra 1935 ii, p. 9), por lo que las generaciones "salen de nuestras aulas secundarias sin orientación alguna acerca del 'behavior' étnico a seguir; o lo que es peor, que salen los unos, con los prejuicios raciales que el error y el desconocimiento total de dicho problema, han labrado en sus corazones" (1935 ii, p. 9). Por ende, propuso que en las aulas se realizasen exposiciones de personajes de ambas razas, en tanto servirían de ejemplos de "modelos de honor" (1935 ii, p. 9) para crear "una raza nueva cubana, la que Martí llama de 'hombres superiores'. Esta raza nueva realizaría por su predominio moral-cívico nuestra unidad nacional" (1935 ii, p. 9). De modo que la autora establece una relación entre educaciónprogreso-unidad nacional inspirada en los ideales de la Independencia y de José Martí1 ${ }^{18}$, intelectual que constantemente es citado en Adelante. En efecto,

\footnotetext{
17 "The belief in education and adoption of conservative and elitist values, such as gender roles, family stability, high moral values, and decency".

${ }^{18}$ Como explica Alejandro de la Fuente (2000), la retórica de la fraternidad racial fue utilizada durante el periodo preindependentista para seducir a los afrocubanos a luchar por la Independencia de Cuba. José Martí fue el intelectual nacionalista que mejor representó ese ideal de una república "con todos y para todos", convirtiéndose "en el evangelio de la ideología nacionalista cubana" (p. 47).
} 
la obra del "apóstol" fue reapropiada por los editores de la revista para reforzar el sentimiento patriótico nacional inspirado en la idea de que "Cuba es más que blanco, más que mulato, más que negro" (Martí, 1936 viii, p. 5). Buscaron, en ese sentido, eliminar las diferencias raciales para reforzar la idea de la cubanidad como un conglomerado de negros y blancos en fraternidad, superponiendo la identidad nacional a la racial. En consonancia con esta idea, Consuelo Serra aludió a una "raza nueva cubana", aunque asociando la "raza" a determinadas características que le serían propias. Por ejemplo indicó que la "conquista de la raza negra, que ha de ser definitiva consistirá en un reconocimiento espontáneo de su propia personalidad y del respeto y consideración que ella se debe a sí misma como raza" (1935 iv, p. 10). Con este ejercicio la autora acabó subsumiendo una pluralidad en una identidad. Esta misma relación entre "raza" y características de los individuos se deja ver en el pensamiento de Calixta Hernández (1936 xv) de un modo aún más explícito cuando afirmó que el negro es "generoso, abnegado, leal, sano de cuerpo y de alma, en su feliz ignorancia del bien y el mal" (p. 20), reproduciendo los estereotipos que fijan a los grupos subalternos como menores de edad, al verlo como un ser bueno e inocente. Esto nos demuestra que hacia la década de 1930 existía aún una gran tensión en torno a la idea de "raza" ${ }^{19}$, pues mientras los intelectuales antirracistas buscaron combatir la inscripción de cualidades denostadoras hacia los sujetos producto

\footnotetext{
${ }^{19}$ Durante la década de 1930 el concepto de "raza" en América Latina fue sometido a revisiones y reelaboraciones desde distintos espacios, siendo cuestionado como criterio de clasificación de la personalidad o del nivel cultural de los sujetos. Uno de los intelectuales que más contribuyó en esta dirección fue Fernando Ortiz, quien desde esta década y a través de la revista de estudios afrocubanos (1937-1940; 1945-1946), difundió sus reflexiones al respecto: "La cubanidad no la da el engendro; no hay una raza cubana. Y raza pura no hay ninguna. La raza, al fin, no es sino un estado civil firmado por autoridades antropológicas; pero ese estado racial suele ser tan convencional y arbitrario y a veces tan cambiadizo, como lo es el estado civil que adscribe los hombres a tal o cual nacionalidad" (Ortiz, 1939 iii, p. 3). Al des-inscribir la idea de "raza" a la de comportamiento dejó el camino abierto para analizar a los grupos humanos en base a su cultura: "Para comprender el alma cubana no hay que estudiar las razas sino las culturas. En una misma raza hay culturas distintas" (1939 iii, p. 8). Asimismo, en la revista Adelante vemos las disímiles lecturas a las que fue sometido el vocablo, y con ello las tensiones que suscitó. En efecto, mientras algunos intelectuales defendieron postulados biológicos sobre la raza: "El negro, salvo raras y honrosas excepciones, y constituyendo un fenómeno biológico al no adoptar el natural instinto de defensa, acepta dócilmente su situación con un fatal conformismo... Ese espíritu de indefensión de nuestros antecesores, forzosamente tenía que constituir una tara hereditaria para nosotros" (Salas Aranda, 1938 xxxvii, p. 13); otros afirmaron que "la raza es una pura expresión física. Se la emplea para clasificar a los individuos de acuerdo con su tinte, su color, con la naturaleza de sus cabellos o de sus ojos, con su estatura, con su corpulencia, y, más particularmente, con la forma de su cabeza. La idea de que existen diferencias mentales entre los pueblos de razas diferentes, se funda sobre un prejuicio más que sobre hechos" (Reclan, 1938 xxxiv, p. 6).
} 
de una "raza" - y con ello contrariar la tesis del de la inferioridad biológica- en circunstancias se valieron de esta misma lógica para apelar a la personalidad del negro o para asignarle características que lo definían como individuo ${ }^{20}$.

Con todo, el proyecto racial de Adelante consistió en relevar la figura del negro a un plano moral destacado. Por ende, Serra (2011) se apropiará de los valores que habrían guiado a los líderes negros, haciéndolos "nuestros", "porque los negros cubanos hemos hecho muchas cosas buenas y dignas, en todas las fases de la vida cubana y esto no siempre mediocremente sino también de manera distinguida y saliente" (p. 97). El objetivo entonces sería sacar a la luz pública estos logros de los individuos de color, complementándolo con una labor educativa recreacional, mediante la organización de festivales, promoción del deporte "o con representaciones teatrales que lejos de oprimir, elevan el nivel social de la raza negra" (Serra, 1936 viii, p. 14). Este proyecto educativo permitiría avanzar hacia una formación espiritual con sentimiento patriótico, abandonando la educación materialista que a sus ojos reinaría en la Cuba actual.

\section{Hogar y eugenesia}

Como se ha visto en los apartados anteriores, la identidad de las mujeres en el discurso de las afrocubanas de Adelante se encuentra profundamente determinada por su rol de madres tanto a nivel privado como público. Alegorías como "madre de la civilización" (Aguilera, 1937 xxvii, p. 10) o "madre del mundo" (Tejo, 1937 xxv, p. 9) buscaron instalar la idea de que la labor de la mujer, si bien se iniciaba en el hogar, tenía proyecciones que podían extenderse a la nación y a la humanidad. Dicha labor se basaría en cualidades propias de la mujer, como la paciencia, el amor a la familia o su sensibilidad. Esta última característica la haría "más apta para resolver los problemas del espíritu, del sentimiento" (Echegoyen, 1935 iv, p. 16). Para reforzar esa identidad las adelantistas contrastaron su figura con la del hombre, caracterizándolo como individuo "hecho para servir los fines de la fría razón" (1935 iv, p. 16.). Es menester señalar que estas construcciones de la identidad femenina no son particulares de las escritoras analizadas, sino que forman parte de inscripciones discursivas del movimiento feminista a nivel latinoamericano, como lo ha demostrado Asunción Lavrin (2005). La autora reconoce la importancia que

\footnotetext{
${ }^{20}$ Miguel Arnedo-Gómez (2016) advierte esta ambivalencia al interior de la revista Adelante a partir de los escritos de Jimenes Grullón, Alberto Arredondo y Oscar P. Alacán, ya que defendían la existencia de razas "As they uphold the existence of races while contradicting theories about mixed-blood degeneracy" (p. 12).
} 
tuvo este discurso para resituar el rol de las mujeres en el espacio público, ya que "al redefinir la maternidad como función social, 'modernizaron' su papel de acuerdo con una situación política nueva, sin alterar ciertos aspectos del fondo tradicional de la maternidad" (p. 19). El feminismo cubano es emblemático a este respecto en tanto todas las discusiones se encontraban imbuidas "de una veneración por la maternidad tradicional" (Stoner, 1992, p. 102). Pero si algo diferenció a las afrocubanas adelantistas de las dirigentes del movimiento feminista fue su especial preocupación por la condición de "clase" y prejuicio racial que impedía a las mujeres y hombres de color constituir matrimonios u hogares estables y hacerse cargo de la crianza de los hijos. Por ejemplo, Calixta Hernández (1935 vi) advirtió, a propósito de la crisis de la institución matrimonial, que los hombres negros tenían dificultades aún mayores para poder construir familias estables en tanto eran "azotados por el prejuicio como faltos de toda protección" lo que les imposibilitaba el acceso a "empleos decorosos que les permitan constituir un hogar con todas las de la ley" (p. 16). Por su parte, Cloris Tejo se alzó en contra de la Convención de Sociedades Negras por la condena que sus integrantes realizaron hacia los padres que enviaban a sus hijos menores de 12 años a vender periódicos. Denunció que la Convención solo trataba los problemas de la "aristocracia negra", sin tomar en cuenta la situación de los negros de clase baja que realmente enviaban a sus hijos a trabajar por no tener los recursos suficientes para mantener a sus familias. Dejó entrever que quién más debía soportar la miseria de la pobreza era la mujer negra, y que sin embargo "ésta recibe no sólo la discriminación de parte del blanco ignorante, sino también del negro que escala los peldaños de la política y el saber" (Tejo, 1938 xxxiv, p. 5). Con este enunciado, la afrocubana demostró que existían tensiones de "clase" y de "género" al interior del mismo movimiento negro. Finalmente, develó que el problema no era producto de la degeneración moral de los negros, sino de índole económica:

Como mujer en general; como mujer negra, futura madre de un hijo cuyo porvenir por razón de herencia no ha de ser nada sonriente, $y$, en nombre de todas las mujeres blancas y negras que tienen que mandar a sus hijos a vender periódicos y es más, mandar a su hija o permitir que vaya en pos del vicio y la prostitución obligadas por la situación económica y no por la degeneración moral, alzo mi humilde voz de protesta ante la Convención Nacional de Sociedades Cubanas que ha tomado la aludida determinación so pretexto de gran parte de abandono. Mujeres negras y blancas: esto nos demuestra que, así como la liberación de los trabajadores ha de ser obra de los trabajadores mismos; también la liberación moral y económica del negro pobre ha de ser obra de los negros pobres mismos (1938 xxxiv, p. 5). 
La asociación que ambas escritoras establecieron entre la dificultad para dar una crianza digna a sus hijos y las condiciones materiales de existencia de los negros forma parte de un intento generalizado de los afrocubanos por atribuir los males de su situación a factores socioeconómicos en vez de a una supuesta inferioridad racial. En efecto, desde la década de los treinta se produjo un esfuerzo intelectual para comprender la pobreza, la mortalidad, entre otros conflictos que aquejaban a los negros, en relación con las condiciones de contexto social, histórico o económico (De la Fuente, 2000, p. 223). Cabe destacar que a pesar de la conciencia de estos obstáculos, las adelantistas no dejaron de promover un discurso maternal ideal que para las mujeres negras de clase baja era muy difícil mantener en sus contextos de vida. Esta contradicción entre lo que las intelectuales afrocubanas esperaban de la identidad femenina en el hogar y las mismas condiciones materiales que ellas sabían que las y los negros pobres debían afrontar, no fueron resueltas ni problematizadas más allá $^{21}$. Entonces ¿qué perspectivas u opciones visualizaron las intelectuales afrocubanas para resolver esta precariedad? Las adelantistas pensaron que la eugenesia podía ayudar a mejorar la precariedad de las familias negras. Ana Echegoyen, Elia Aguilera y Ángel Pinto apoyaron esta política tan fomentada y discutida durante la primera mitad del siglo XX. La eugenesia gozó de mucho apoyo por parte del movimiento feminista latinoamericano, en tanto las mujeres consideraron que podía mejorar la salud de los hijos (Lavrin, 2005, p. 24), o que contribuiría a la emancipación femenina ${ }^{22}$. ¿Cuáles son los argumentos de las afrocubanas para respaldar la eugenesia? Ana Echegoyen visualizó la eugenesia como parte de las conquistas del ser humano, como un verdadero avance hacia la perfección que podría frenar las malas decisiones de las jóvenes madres al momento de contraer matrimonio. Para ella existía una falta de reflexión por parte de la juventud, puesto que no se preguntaba "¿qué condiciones se requerirán en mi futuro esposo, para que mi prole tenga las cualidades que prefiero?" (Echegoyen, 1935 vi, p. 14). El diagnóstico que realizó la pedagoga

\footnotetext{
${ }^{21}$ En el último número de Adelante se publica un artículo de Cecilia Eggleston, una afroamericana que explicita todos los conflictos y dudas que vive la mujer negra al momento de ser madre, en tanto las estadísticas demuestran que "el promedio de la mortalidad de la mujer negra por causa de alumbramiento es diez veces mayor que la de las blancas" (Eggleston 1939 XLIV-XLV, p. 7). Afirma que aún en el caso de que la mujer logre sobrevivir y ser madre se enfrenta a la discriminación racial, pobreza, falta de cultura y educación que sufrirá su hijo.

${ }^{22}$ Por ejemplo, Nadia Ledesma (2014) ha demostrado para el caso argentino que los médicos anarquistas buscaron implementar la eugenesia para que la mujer pudiera controlar la natalidad, liberándolas de los obstáculos domésticos, de modo que se potenciaba la posibilidad de la mujer de decidir sobre su propio cuerpo.
} 
fue que las decisiones de muchas mujeres estaban guiadas por "los ciegos impulsos de la apetencia sexual" (1935, vi, p. 14). Este predominio del impulso por sobre la racionalidad en "su prole" era lo que necesitaba ser frenado. Por su parte, Ángel Pinto apoyó la idea de que la mujer debía cuidar su cuerpo y "hacerlo digno del alma que lo envuelve", evitando que fuera preso de "las fuerzas ciegas del instinto", en tanto

Los matrimonios negros siempre fueron pobres, pero desgraciadamente, cada día tienden a serlo más... El negro, cuyos medios económicos tienden a ser cada día más limitados e inseguros, debe velar por la limitación de sus hijos -legítimos o no- para disminuir el porcentaje que el negro da a la demografía, a la criminalidad, a la prostitución $y$, en general, a todos los vicios, males oriundos todos de la miseria y la incultura en que vive el hombre de color (Pinto, 1936 xiii, p. 4).

Su argumento se apoyaba en el jurista y político español, Luis Jiménez de Asúa (1929), quien en su libro Libertad de amar y derecho a morir, entregó tres argumentos para implementar la eugenesia: el riesgo de salud de la madre, las dificultades económicas para tener más hijos y el derecho de la mujer de decidir sobre su cuerpo (pp. 62-68). Sin embargo, Ángel Pinto solo rescató los dos primeros argumentos de Asúa, sin validar el derecho de la mujer de limitar, por razones personales, su deseo de ser madre. Para los adelantistas era sumamente problemático que la delincuencia o criminalidad se siguiera asociando a los negros en tanto alimentaba los prejuicios racistas con los que ellos debían convivir cotidianamente, por lo que insistieron en la necesidad de acabar con estos vicios dentro de los matrimonios negros y así, con la "desmoralización de la familia" (Pinto, 1936 xiii, p. 4). Es probablemente por este motivo que Elia Aguilera aconsejó educar a la mujer en la eugenesia, de modo que fuera capaz de construir hogares estables y respetables, dignos de la honorabilidad que los adelantistas quisieron promover a través de los principios de mejoramiento cultural y social de su propia organización. Pero esa 'revolución en el hogar' tan anhelada por el movimiento feminista en su conjunto, chocaba con la realidad de las mujeres negras, en la medida que los prejuicios raciales y las condiciones económicas dificultaban cumplir con tan altos estándares de ser femenino. De modo que las intelectuales afrocubanas, si bien repararon en muchas de las desigualdades que las mujeres negras debían afrontar, no cuestionaron los enunciados sobre la virtud maternal, ni menos la imposibilidad de su aplicabilidad en las clases populares negras. Antes bien, interpelaron a sus lectoras negras para que intentasen cumplir con dichos 
patrones, y así, pudiesen convertirse en ejemplos de civilización y progreso para el avance de su "raza" y de la humanidad.

\section{Conclusiones}

Aunque las posibilidades de que las mujeres negras pudiesen convertirse en letradas dentro de Cuba eran escasas, ciertas circunstancias y procesos históricos permitieron que algunas efectivamente se posicionaran como intelectuales, exponiendo públicamente su pensamiento sobre los problemas que las interpelaban en términos de "género" y de "raza". La revista Adelante fue uno de los pocos espacios en que pudieron expresar sus propuestas de cambio dentro de un contexto que llamaba a una transformación radical del país. Así, fueron capaces de develar las dificultades más importantes que en el terreno social afrontaban las mujeres negras producto de la precariedad económica y/o la discriminación racial que sufrían. Problematizaron los juicios condenatorios que otras sociedades negras realizaron en contra de las mujeres de color que se veían obligadas a enviar a sus hijos a vender periódicos, y advirtieron sobre la imposibilidad de los negros de tener matrimonios y hogares estables por pertenecer a las clases populares. Al poner en el debate público que estos problemas eran producto tanto de su situación socioeconómica como de los prejuicios raciales que seguían imperando, hicieron frente a los argumentos que sostenían que el lugar que los negros ocupaban en la república era producto de su inferioridad biológica.

Las feministas de Adelante practicaron una labor educacional basada en construir por una parte, una revolución en el hogar, y por otra un pensamiento crítico en torno al racismo, proponiendo fomentar la unidad racial y visibilizar los aportes que la población de color había entregado al país. Ambas estrategias buscaron reposicionar el rol de mujeres y negros a nivel social con el fin de incorporarlos en condiciones de igualdad a la nación. En este intento de resituar públicamente sus roles, reprodujeron algunos de los estereotipos con que históricamente se había identificado a ambos sujetos. En efecto, enarbolaron un discurso que fijaba la identidad de la mujer como madre, y atribuyeron a los afrocubanos cualidades asociadas a la "raza", como la inocencia y el desconocimiento del bien y el mal. Estas articulaciones les llevaron a levantar un proyecto de transformación basado en una revolución en el hogar que tendría como protagonista a la mujer. Ella se haría cargo de entregar valores espirituales a la nación, entre los cuales la unidad racial de blancos y negros constituía un pilar fundamental para fundar una nueva cubanidad sustentada en el amor y la solidaridad. De modo que su estrategia 
consistió en integrar a los grupos subordinados mediante estrategias de adaptación y no a partir de un cuestionamiento a los postulados tradicionales creados por las clases dominantes.

\section{Referencias}

Acuña Lazcano, Tomás (1938). "Societarias". Adelante, iv (xxxvii), pp. 17-20.

Aguilera Martínez, Elia (1937). "Consideraciones sobre la mujer y su cultura". Adelante, iii (xxvii), pp.10-20.

Alarcón, Agustín (1937). “¿Nación negra? ¡No!”. Adelante, iii (xxvii), p. 12.

Arnedo-Gómez, Miguel (2016). Uniting Blacks in a Raceless Nation: Blackness, Afro-Cuban Culture, and Mestizaje in the prose and poetry of Nicolás Guillén. USA: Bucknell University Press.

Arredondo, Alberto (1939). El negro en Cuba. La Habana: Alfa.

Brunson, Takkara (2011). Constructing Afro-Cuban Womanhood: Race, Gender, and Citizenship in Republican-Era Cuba, 1902-1958. Tesis doctoral. The University of Texas at Austin, Texas, United State.

De la Fuente, Alejandro (2000). Una nación para todos. Raza, desigualdad y politica en Cuba.1900-2000. Madrid: Editorial Colibrí.

Echegoyen de Cañizares, Ana (1936). "Para la mujer. Un fracaso político que podemos transformar en triunfo". Adelante, $i(\mathrm{x}), \mathrm{p} .11$.

Echegoyen de Cañizares, Ana (1935). "Para la mujer. Del cultivo de las cualidades específicas de la mujer, dependerá en gran parte, el futuro de la humanidad". Adelante, $i$ (iv), pp. 16 - 18.

Editores (1938). "Una sociedad negra que enaltece a Cuba. Breve reseña de la Asociación Adelante”. Adelante, iii (xxxvi), pp. 13-14.

Editores (1937). "De interés". Adelante, iii (xxvii), p. 4. 
Editores (1937). "Mujer y Sociedad”. Adelante, ii (xxi), p. 3.

Editores (1936). "Primer aniversario". Adelante, ii (xii), p. 5.

Editores (1935). “Cubanos. Alerta!". Adelante, i (iv), p. 5.

Editorial. (1937). “¡Mujeres!”. Mujeres libres, (7), s/p.

Gronbeck-Tedesco, John A. (2015). Cuba, the United States, and the Culture of the Transnational Left, 1933-1970. New York, USA: Cambridge University Press.

Guridy, Frank Andre (2010). Forging Diaspora: Afro-Cubans and African Americans in a World of Empire and Jim Crow. Chapel Hill, USA: University of North Carolina Press.

Hernández de Cervantes, Calixta (1938). "Mujeres ejemplares: Ana Etchegoyen". Adelante, iii (xxxiii), p. 13.

Hernández de Cervantes, Calixta (1936). "La mujer opina". Adelante, ii (xv), pp. 11, -20.

Hernández de Cervantes, Calixta (1936). "Horizontes". Adelante, ii (xiv), p. 8.

Hernández de Cervantes, Calixta (1935). "Feminismo". La crisis del matrimonio. Adelante, $i$ (vi), p. 16.

Hernández de Cervantes, Calixta (1935). "Feminismo". La mujer y la política. Adelante, i (iv), pp. 7 - 20.

Hernández de Cervantes, Calixta (1935). "Feminismo". Adelante, $i$ (ii), p. 14.

Jiménez de Asúa, Luis (1929). Libertad de amar y derecho a morir. Ensayos de un criminalista sobre eugenesia, eutanasia, endocrinología. España: Historia Nueva.

Martí, José (1936). “Mi raza. Adelante”, $i$ (viii), pp. 5 - 8. 
Lamas, Marta (2000). "Diferencias de sexo, género y diferencia sexual". Cuicuilco Nueva época, 7 (18), pp. 1-24.

Lavrin, Asunción (2005). Mujeres, feminismo y cambio social en Argentina, Chile y Uruguay 1890-1940. Santiago de Chile: LOM ediciones.

Ledesma, Nadia (2014). "La maternidad consciente y voluntaria como estrategia para la emancipación sexual femenina". Cuadernos de H Ideas, 8 (8), pp. 1-19. Disponible en: http://perio.unlp.edu.ar/ojs/index.php/cps/ article/view/2118/2076.

Ortiz, Fernando (1939). "La cubanidad y los negros". Estudios afrocubanos, iii (1-4), pp. 3-15.

Pinto, Ángel C. (1936). "La mujer negra y la maternidad consciente". Adelante, ii (xiii), p. 4.

Portuondo Calá, P. (1935). "Palabras". Adelante, i (ii), pp. 17-22.

Ramírez Chicharro, Manuel (2016). "El activismo social y político de las mujeres durante la República de Cuba (1902-1959)". Revista Eletrônica da ANPHLAC, 20, pp. 141-172.

Ramírez Chicharro, Manuel (2014). "Doblemente sometidas: las «mujeres de color» en la república de Cuba (1902-1959)". Revista de Indias, LXXIV (262), pp. 783-828.

Reclan, Lord (1938). “¿La raza pura? - ¡Un mito!”. Adelante, iii (xxxiv), p. 6.

Rubiera, Daisy (2011). “Apuntes sobre la mujer negra cubana”. Cuban Studies, 42, pp. 176-185.

Sabas Alomá, Mariblanca (2003). Feminismo. Cuestiones sociales y crítica literaria. Cuba: Editorial Oriente.

Salas Aranda, Mariano (1938). "Fatal conformismo del negro". Adelante, iv (xxxvii), p. 13.

Scull, Ángel Alonso (1935). “¡Nunca!”. Adelante, i (iv), p. 20. 
Serra, Consuelo (2011). "Nuestros valores étnicos". En Rubiera Castillo, D. y Martiatu, I. M. (Comp.), Afrocubanas. Historia, pensamiento y prácticas culturales (pp. 96-97). Cuba: Editorial de Ciencias Sociales de La Habana.

Serra, Consuelo (1936). "Pedagógicas". Síntesis. Adelante, i (viii), p. 14.

Serra, Consuelo (1935). "Pedagógicas. La educación y los problemas sociales". Adelante, $i(\mathrm{v})$, pp. 10-18.

Serra, Consuelo (1935). "Pedagógicas. Nuestros adolescentes deben constituir la esperanza de la Patria Cubana". Adelante, i (ii), p. 9.

Stoner, K. Lynn (1992). De la casa a la calle. El movimiento cubano de la mujer en favor de la reforma legal (1898-1940). Madrid: Editorial Colibrí.

Tejo, Cloris (1938). "La mujer trabajadora ante el Congreso Femenino y la Constituyente". Adelante, iv (xxxix), pp. 15-20.

Tejo, Cloris (1938). "En torno a la convención de sociedades negras". Adelante, iii (xxxiv), p. 5.

Tejo, Cloris (1937). “Orientación femenina”. Adelante, ii i (xxv), p. 9.

Urrutia, Gustavo (1935). "Panorama". Adelante, i (ii), pp. 6-7-22.

Urrutia, Gustavo (1933). “Perspicacia Femenina”. Diario La Marina, p. 14.

Urrutia, Gustavo (1928). “Armonías”. Diario la Marina, p. vi.

Whitney, Robert (2001). "Observaciones sobre el Estado y la revolución en Cuba. 1920-1940". Temas, (24-25), pp. 87-197.

Yañez, Mirta (2003). Camila y Camila. Cuba: Ediciones La memoria. 